\title{
Singuagens
}

\section{PODER E DISCIPLINARIZAÇÃO NO SISTEMA PRISIONAL: USO PROGRESSIVO DA FORÇA}

\author{
Adélli Bortolon Bazza (UEM)
}

\begin{abstract}
RESUMO: O sistema prisional paranaense enfrentou, nos anos de 2014 e 2015, uma série de rebeliões. Nessas manifestações, os presos reclamavam de opressão da parte dos funcionários. Diante desse cenário, propõe-se analisar as práticas de disciplina nos ambientes prisionais, em especial, o uso progressivo da força. Para tanto, foram levantadas as leis que regem como as penas devem ser cumpridas e qual o tratamento deve ser dispensado ao e pelo condenado e também as orientações técnicas que os funcionários recebem acerca de seu modus operandi. Esses documentos foram relacionados à teoria sobre a disciplinarização dos corpos proposta por Foucault. A análise demonstrou que as práticas do sistema prisional paranaense vão ao encontro das práticas descritas por Foucault, na medida em que evitam tocar nos corpos ou puni-los, estabelecendo a disciplina e o poder por meio da vigilância e da docilização dos corpos, em detrimento de ações de punição física.
\end{abstract}

PALAVRAS-CHAVE: Poder. Disciplinarização. Uso progressivo da força.

ABSTRACT: The penal system of Parana has dealt, in the years of 2014 and 2015, with a series of rebellions. In those riots, the prisoners complained of officers' oppression. In view of this scenario, it is proposed that the disciplinary practices in the prison environment, especially the progressive use of force be analyzed. Therefore, the laws which regulate the way a sentence should be served were gathered, as well as the treatment required of and given to the convict, and also the technical guidance provided to the staff regarding their modus operandi. These documents were correlated to the theory on the disciplinarization of bodies proposed by Foucault. The analysis demonstrated that the practices of Parana's penal system concurs with the practices described by Foucault, since they avoid touching or punishing bodies, establishing power and discipline through surveillance and by making bodies docile, in lieu of physical punishment.

KEY-WORDS: Power. Disciplinarization. Progressive use of force.

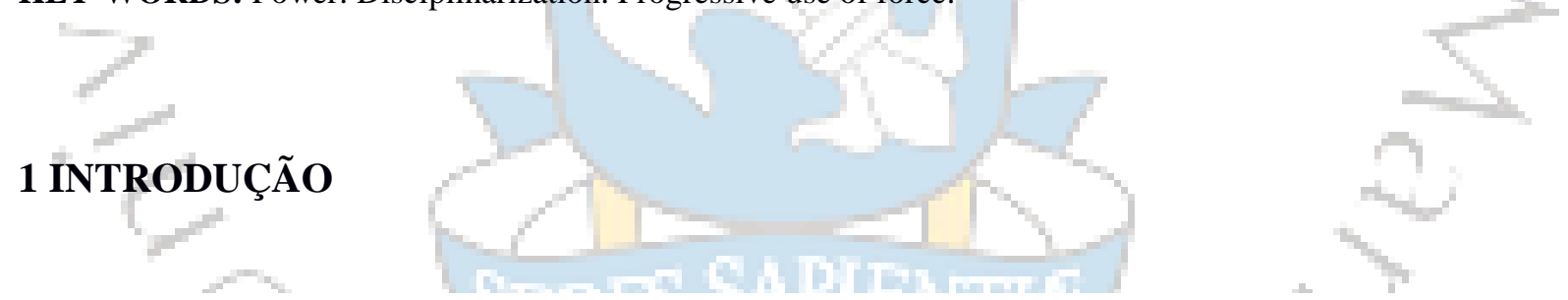

Os anos de 2014 e 2015 foram marcados por rebeliões em diversos presídios do Paraná. A mais recente onda teve início em Cascavel, onde se manifestou com um alto índice de violência, causando cinco mortes e deixando cerca de vinte e cinco feridos, entre agentes e presos. Essas ações se estenderam por unidades prisionais de todo o estado, gerando rebeliões também em Piraquara, Cruzeiro do Oeste, Guarapuava e Maringá, nas quais agentes penitenciários foram tomados como reféns, num total de 24 rebeliões por todo o estado. As reivindicações mais comuns foram a transferências de presos entre unidades, melhorias na alimentação e o fim de alguns procedimentos como o uso de algemas na movimentação de presos e a revista íntima em visitantes. Essas manifestações figuram como um acontecimento 


\section{S Linguagens}

no qual se produzem discursos sobre o apenado, sobre o sistema penitenciário e também sobre as formas de punição da sociedade contemporânea.

Tal produção discursiva dá visibilidade a um espaço normalmente não visível ao olhar da sociedade: as prisões e suas mazelas. Nesse espaço, criado para a supressão da liberdade, detentos e profissionais da área enfrentam uma conjuntura com muitas outras privações. Entre os problemas enfrentados no atual sistema penal destacam-se: a falta de estrutura nos estabelecimentos prisionais; superlotação nas unidades; ociosidade forçada dos detentos; dificuldade de acesso à assistência jurídica e de atendimento médico, odontológico e psicológico; condições de vida e higiene precárias e elevado índice de reincidentes que passam por uma pena privativa de liberdade.

Focalizando a prisão como um ambiente de poder e de resistência, em que há uma alta periculosidade tanto para os detentos quanto para os profissionais, este trabalho tem por objetivo observar o papel que os procedimentos de segurança desempenham sobre os corpos dos indivíduos a eles submetidos, como ferramentas de controle que refletem diretamente na segurança de um estabelecimento prisional. Cumpre, portanto, investigar se os procedimentos de segurança podem ser considerados uma estratégia de vigilância no poder disciplinar.

Entre os procedimentos de segurança comuns ao ambiente prisional estão a revista pessoal e o uso de algemas, os quais costumam ser objeto de reclamação da parte dos detentos em rebeliões. Segundo o Caderno de Segurança (2011), a revista pessoal é ato pelo qual o agente penitenciário procede à revista em alguém para verificar se este não porta algum material não permitido e que possa oferecer risco à integridade física de qualquer pessoa dentro da unidade penal, ou outro não permitido portar por medidas de segurança, enquanto estiver nas dependências da unidade. Tal revista deve ser efetuada toda vez que um detento é retirado de sua cela e quando vai ser devolvido a ela, novamente.

De acordo com orientações do Estatuto Penitenciário do Paraná (1995), o uso de algemas é meio de coerção a ser utilizado, tal como a camisa de força, como medida de precaução contra fuga ou durante o deslocamento do preso ou do internado. Esses recursos devem ser retirados quando do comparecimento em audiência perante a autoridade judiciária ou administrativa; por motivo de saúde, segundo recomendação médica; em circunstâncias excepcionais, quando for indispensável utilizá-los em razão de perigo iminente para a vida do preso, do internado, do servidor ou de terceiros (Estatuto Penitenciário do Paraná, artigo 58, I, 


\section{Singuagens}

II e III).

Espera-se que tais procedimentos possam ser empregados de forma pacífica da parte dos funcionários para com os apenados. Porém, como a aplicação da lei é uma das tarefas elementares no sistema prisional, admite-se que seja utilizada a força em determinadas circunstâncias, na medida necessária e adequada, observando-se os princípios éticos e legais de necessidade e proporcionalidade no cumprimento do dever legal. De acordo com instrução do Caderno de Segurança (2011), que orienta o trabalho dos agentes penitenciários, "força é toda intervenção compulsória sobre o indivíduo ou grupos de indivíduos, reduzindo ou eliminando sua capacidade de autodecisão”. Assim como a revista íntima e o uso das algemas, às vezes o uso da força é necessário para a manutenção da disciplina, da ordem e da segurança no ambiente prisional.

Visando à padronização e à legalidade dos procedimentos adotados, o Estado do Paraná criou um caderno de procedimentos, uma espécie de código de conduta no trato com o interno, baseando-se na legislação penal atual, bem como em documentos como o Código de Conduta para os Encarregados da Aplicação da Lei (CEEAL - resolução 34/169 de 19 de dezembro de 1979). Tais leis e cadernos de orientações podem ser relacionados à compreensão foucaultiana sobre a disciplina com a finalidade de entender como essas medidas refletem sobre o corpo do encarcerado. Para tanto, inicialmente, serão retomadas as reflexões de Foucault a respeito das formas de disciplinarização do corpo. Na sequência, serão apresentados os pressupostos básicos da Lei de execução Penal e a forma como essas orientações são apresentadas como condutas no Caderno de Segurança utilizado pelo Departamento Penitenciário (DEPEN). Por fim, serão cotejadas as práticas apresentadas por Foucault como próprias ao controle dos corpos e as práticas de segurança aplicadas atualmente no sistema prisional do Paraná, de modo a refletir sobre as permanências e os deslocamentos das práticas de controle dos corpos previstas pelo teórico na atualidade.

\section{PODER E DISCIPLINA}

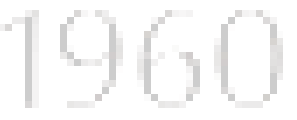

As relações sociais e políticas materializam o encontro de interesses e objetivos diferentes e até conflitantes, o que é natural, dada a pluralidade do corpo social, as quais são sempre permeadas por relações de poder. Elas ocorrem tanto nas situações mais cotidianas e 


\section{Linguagens}

menos visíveis, como relações as de amizade, quanto nas mais institucionalizadas, em que o exercício do poder é mais visível, como é o caso das relações entre Estado (representado por suas leis e funcionários) e detentos.

Devido à relevância do poder para a compreensão das relações que se desenvolvem em uma sociedade, ele já foi tradicionalmente abordado por grande parte da filosofia política e pelas ciências políticas como um todo. Entretanto, não se pode afirmar que se trata de um tema suficientemente esgotado ou superado. Pensar o poder é sempre um campo aberto, tendo em vista que as relações de poder na sociedade acompanham a mutabilidade e a fluidez das relações humanas. O tratamento foucaultiano do poder assume essa visão não sistemática, tendo em vista que Foucault não produziu uma teoria geral do poder bem definida e explícita. Em suas análises, o poder é considerado um conjunto de procedimentos presente nas práticas sociais e, consequentemente, construído historicamente. Desse modo, não é possível caracterizá-lo de maneira definitiva, posto que sua mutabilidade lhe permite assumir diferentes configurações ao longo do tempo.

Rompendo com uma tradição marxista que analisava o poder por meio da luta de classes, Foucault apresenta uma analítica do poder que o compreende, não como algo que se detém, mas como algo que exerce. Trata-se de uma série de redes de relações sobre as quais se forma a sociedade, e que incidem sobre os indivíduos a fim de garantir a coesão do corpo social. Na introdução da obra Microfísica do Poder, Machado (1999, p. XVI) aponta elementos para a compreensão de poder em Foucault e afirma que é preciso se desvencilhar da visão de poder apenas como repressor, pois ele "possui uma eficácia produtiva, uma riqueza estratégica, uma positividade. E é justamente esse aspecto que explica o fato de que tem como alvo o corpo humano, não para supliciá-lo, mutilá-lo, mas para aprimorá-lo, adestrá-lo". Em vez de aplicar uma ação agressiva ou repressiva sobre os corpos, o poder disciplina, produzindo corpos e identidades dóceis.

Conforme, Berth (2013, p. 109), Foucault distingue dois níveis de funcionamento do poder: "um nível disciplinar, no qual se efetua a produção e a individualização dos sujeitos; e um nível jurídico-político, cuja função é mascarar que os processos de sujeição, por natureza, são desiguais e dissimétricos." O poder disciplinar é bastante detalhado, a partir de estudos sobre as técnicas de docilização dos corpos, na obra Vigiar e Punir (1999), na qual Foucault busca discutir por que o encarceramento, a detenção são tidos como formas de punição 


\section{Linguagens}

preferíveis na sociedade contemporânea. Para tanto, é feita uma retomada sobre as formas de punição e controle remetendo à Idade Média, em que os condenados eram supliciados em praça pública.

Sob o domínio do poder monástico, a tortura era uma forma de exercer poder visível sobre o corpo e coibir certos atos por meio do terror. Em substituição a essa forma de punição, a modernidade desenvolve o controle por meio de uma invisibilidade do poder que organiza, vigia e disciplina os corpos. Desde a Antiguidade, a prisão existe como forma de reter os indivíduos, mas tratava-se de um procedimento que garantia o preso ficasse à disposição da justiça para receber o castigo prescrito, entre os quais figuravam a morte, a deportação, a tortura, a venda como escravo etc. Porém, apenas na Idade Moderna, por volta do século XVIII, se dá o nascimento da prisão, com a criação da pena de encarceramento, como "privação de liberdade".

Segundo Fischer (2012, p. 44), o filósofo utiliza “essa descrição para mostrar como há um momento de ruptura com o poder visível, e como a punição irá transformar-se a partir de práticas mais suaves, menos violentas, naquilo que toca os corpos". Essa nova forma de punir impõe aos indivíduos uma vigilância permanente, pois submete todos ao olhar de um poder, pelos mecanismos disciplinares de controle e vigilância que se estabelecem nas práticas do corpo social. Ao lado de uma sociedade democrática, uma sociedade disciplinar. O momento das disciplinas incide diretamente sobre os corpos de modo a torná-los dóceis e úteis. Esse mecanismo possibilita a formação de "uma política das coerções que são um trabalho sobre o corpo, uma manipulação calculada de seus elementos, de seus gestos, de seus comportamentos" (FOUCAULT, 1999, p. 119).

Para o desenvolvimento desse tipo de controle, são empregados, segundo o autor, dispositivos que se encarregariam da eficácia do projeto disciplinar na sociedade moderna. Entre eles, está o modelo do quartel que é aplicado à sociedade por permitir vigilância múltipla. Tal modelo acarretou também uma mudança na arquitetura que passa a ser construída não mais para ser vista, mas para permitir um controle daqueles que nela estão, tornando-os visíveis. Nesse modo de operação, as tarefas de vigilância e físcalização de funcionários fazem parte do sistema da instituição. Dessa forma, ainda que haja um chefe ou diretor, é o próprio aparelho que faz circular o poder, que se exerce em diversas direções. Além disso, a disciplina cria um sistema de recompensas e penalidades contínuas para 


\title{
Singuagens
}

individualizar e classificar as condutas.

Em termos de arquitetura, Foucault (1999) apresenta a figura do Panóptico como um modelo da vigilância. Construída em forma circular, no pátio central ficaria a torre, enquanto no edifício haveria janelas externas e para o pátio interno. Assim, com a entrada da luz do sol, as pessoas colocadas nas celas desse prédio estariam sempre visíveis ao olho do vigilante abrigado na torre. E se sentiriam sempre vigiadas, mesmo que lá não houvesse alguém. Esse modelo serviu como planta para a construção de inúmeras prisões. Isso se justifica porque, de acordo com o autor (1999), a prisão surge para ser uma forma de correção e de educação capaz de transformar o indivíduo pervertido. Suas técnicas de poder passam principalmente pelo "isolamento", logo, a "solidão", a tentativa de "autorregulação pela reflexão" e o "trabalho".

Dessa maneira, o poder disciplinar se autossustenta pelo jogo de olhares calculados, por uma verdadeira "física" do poder:

\begin{abstract}
Graças às técnicas de vigilância, a "física" do poder, o domínio sobre o corpo se efetuam segundos as leis da ótica e da mecânica, segundo um jogo de espaços, de linhas, de telas, de feixes, de graus, e sem recurso, pelo menos em princípio, ao excesso, à força, à violência. Poder que é em aparência ainda menos "corporal" por ser mais sabiamente "físico" (FOUCAULT, 1999, p. 148).
\end{abstract}

Assim, a disciplina se exerce no nível dos indivíduos, "atinge seus corpos, vem se inserir em seus gestos, suas atitudes, seus discursos, sua aprendizagem, sua vida quotidiana" (FOUCAULT, 2009, p. 131). O poder disciplinar penetra de uma forma profunda e sutil nas mais diversas relações sociais constituídas e utiliza a vigilância como uma de suas estratégias e efeito de poder. A aplicação do poder passa do suplício do corpo para aquele que é submetido a um olhar, a um campo de visibilidade.

No ambiente das prisões, a vigilância é frequentemente utilizada como instrumento da disciplina. Ela surge como mecanismo disciplinar a partir do momento em que se verifica que é mais vantajoso vigiar que punir. Isso porque, a punição pode ter um custo político muito alto: se muito violenta, causa rebeliões; se muito fraca, favorece resistências. Consequentemente, o poder externo pode fazer-se ausente, tornando-se incorpóreo e prescindindo de confronto físico. Em suma, quanto mais a visibilidade é internalizada, mais os efeitos de poder são profundos, constantes, definitivos e eficientes.

Linguagens \& Cidadania, v. 19, jan./dez., 2017. 


\section{S Linguagens}

A partir desse olhar, o preso pode ser compreendido como o corpo-sujeito sobre o qual se investe o poder que o controla e, ao mesmo tempo, figura como objeto de produção de saberes, na medida em que seu corpo se oferece e resiste à normalização. Para Fischer (2012, p. 60), "classificado, julgado, exercitado, comparado, diferenciado, hierarquizado, homogeneizado, excluído", - o homem do cárcere incorpora literalmente para Foucault a "arte de punir e de ser punido". Buscamos, a seguir, discutir uma série enunciativa composta de documentos oficiais que objetivam o sujeito detento, bem como as práticas que ele deve desempenhar ao ocupar esse lugar e as práticas que outrem devem aplicar no tratamento com eles, a fim de problematizar de que forma se dá o exercício do poder sobre o corpo em reclusão.

\section{A DISCURSIVIZAÇÃO DA DISCIPLINA EM DOCUMENTOS OFICIAIS}

A Lei $n^{\circ} .7210 / 1984$ - Lei de Execução Penal foi o instrumento criado para servir como guia no processo de controle do corpo do encarcerado, contemplando diversas situações do convívio social dentro das prisões, atribuindo-lhe deveres, direitos e uma disciplina a seguir. No modelo vigente atual, a Lei n. 7.210/84 (LEP) é estudada e aplicada de acordo com a teoria de finalidade das penas. Dessa forma, impingir uma pena implica o respeito aos direitos e garantias fundamentais - respeitando a dignidade da pessoa humana- e visa não só a punir o criminoso, mas também pretende ressocializar o indivíduo apenado, conforme o artigo $1^{\text {a }}$ da Lei de Execução Penal.

Dentre os deveres, cumpre ao condenado, além das obrigações legais inerentes ao seu estado, num caráter intramuros, submeter-se às normas de execução da pena (art. 38 da Lei nº. 7210/1984 - Lei de Execução Penal). Também, segundo esse artigo, faz parte de seu conjunto de obrigações manter um comportamento disciplinado, obedecer ao servidor, respeitar os demais condenados, não se envolver em movimentos de fuga, executar os trabalhos recebidos, submeter-se às sanções disciplinares impostas, manter a higiene pessoal e asseio da cela ou alojamento e conservar seus objetos de uso pessoal. Em caráter extramuros, cabe ao interno indenizar a vítima ou seus sucessores, bem como o Estado, quando possível, das despesas realizadas com a sua manutenção, mediante desconto proporcional da remuneração do trabalho. 


\section{S Linguagens}

Por outro lado, a lei traz normas garantidoras do respeito e bem estar do internado, impondo a todas as autoridades o respeito à integridade física e moral dos presos, tanto condenados quanto provisórios (art. 40, LEP).

O artigo 41 da mesma lei elenca os direitos que lhes são garantidos, a saber:

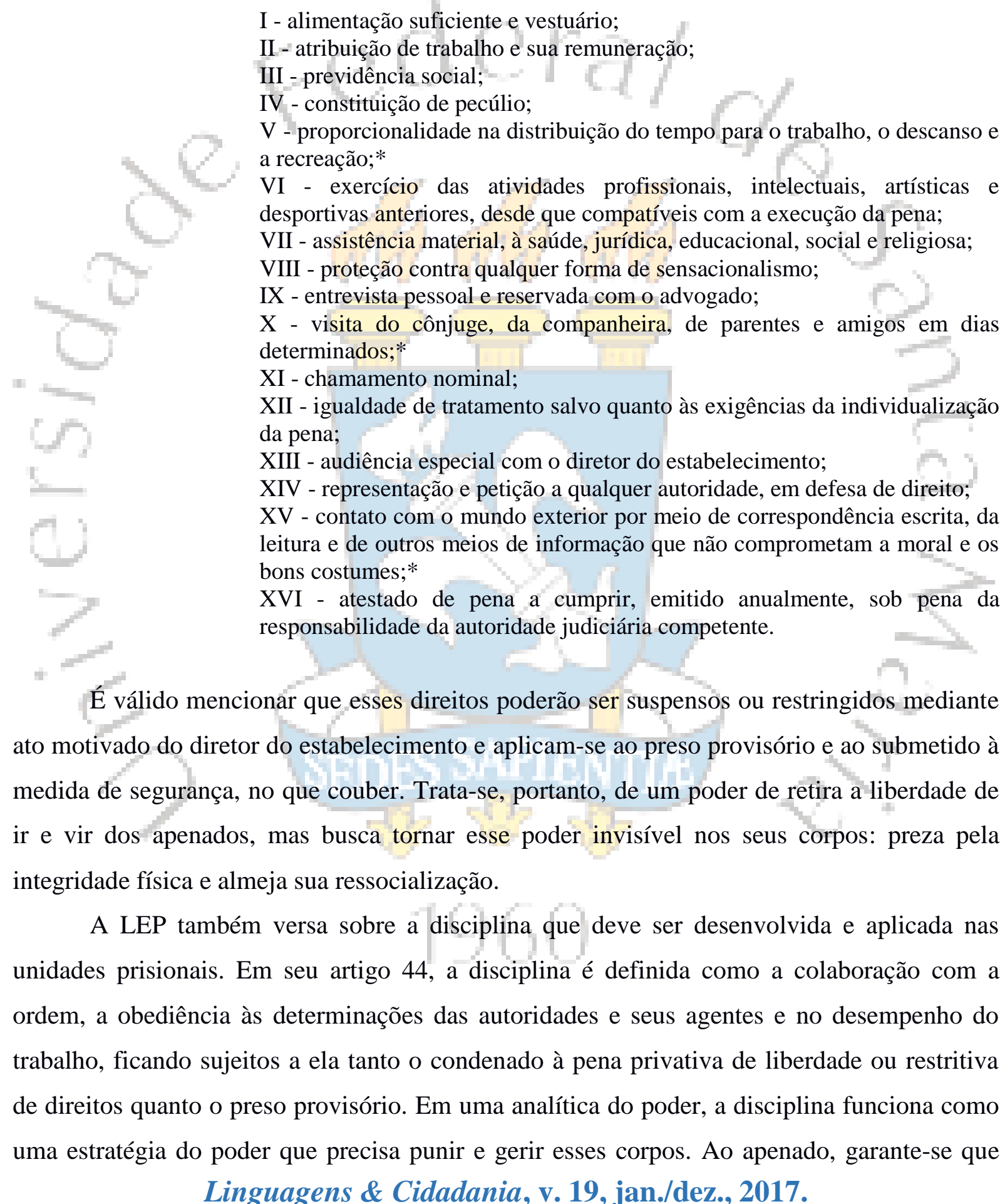

I - alimentação suficiente e vestuário;

II - atribuição de trabalho e sua remuneração;

III - previdência social;

IV - constituição de pecúlio;

$\mathrm{V}$ - proporcionalidade na distribuição do tempo para o trabalho, o descanso e a recreação;*

VI - exercício das atividades profissionais, intelectuais, artísticas e desportivas anteriores, desde que compatíveis com a execução da pena;

VII - assistência material, à saúde, jurídica, educacional, social e religiosa

VIII - protecão contra qualquer forma de sensacionalismo;

- entrevista pessoal e reservada com o advogado

visita do cônjuge, da companheira, de parentes e amigos em dias determinados;

amamento nomin da pena;

XIII - audiência especial com o diretor do estabelecimento

XIV - representação e petição a qualquer autoridade, em defesa de direito;

$\mathrm{XV}$ - contato com o mundo exterior por meio de correspondência escrita, da leitura e de outros meios de informação que não comprometam a moral e os bons costumes;

XVI - atestado de pena a cumprir, emitido anualmente, sob pena da responsabilidade da autoridade judiciária competente.

É válido mencionar que esses direitos poderão ser suspensos ou restringidos mediante

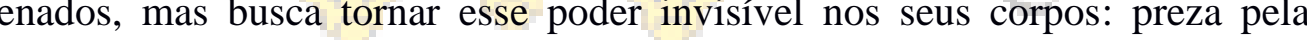

Linguagens \& Cidadania, v. 19, jan./dez., 2017. 


\section{S Linguagens}

não haverá falta nem sanção disciplinar sem expressa e anterior previsão legal ou regulamentar. As sanções não poderão colocar em perigo a integridade física e moral do condenado, sendo vedado o emprego de cela escura, bem como as sanções coletivas. (art. 45, LEP)

O condenado ou denunciado, no início da execução da pena ou da prisão, será cientificado das normas disciplinares (LEP, art. 46) e, caso venha a descumpri-las, caberá à autoridade administrativa responsável pelo condenado, o exercício do poder disciplinar, conforme disposições regulamentares (LEP, arts. 47 e 48). Considera-se que o detento cometeu uma falta grave quando:

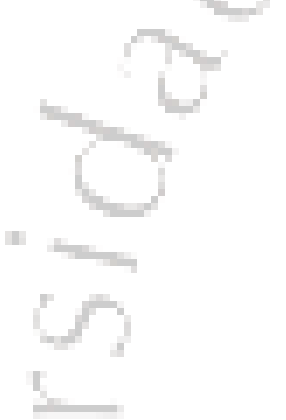

I - incitar ou participar de movimento para subverter a ordem ou a disciplina;

II - fugir;

III - possuir, indevidamente, instrumento capaz de ofender a integridade física de outrem;

IV - provocar acidente de trabalho;

$\mathrm{V}$ - descumprir, no regime aberto, as condições impostas;

VI - inobservar os deveres previstos nos incisos II e V do artigo 39 desta Lei; VII - tiver em sua posse, utilizar ou fornecer aparelho telefônico, de rádio ou similar, que permita a comunicação com outros presos ou com o ambiente externo. (LEP, art. 50)

O controle do poder faz funcionar a disciplina, ao institucionalizar as regras a serem seguidas e prever punições caso haja descumprimento:

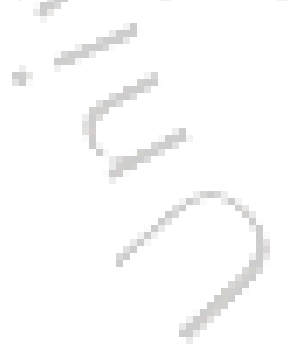

51. Comete falta grave o condenado à pena restritiva de direitos que:

I - descumprir, injustificadamente, a restrição imposta;

II - retardar, injustificadamente, o cumprimento da obrigação imposta;

III - inobservar os deveres previstos nos incisos II e V do artigo 39 desta Lei.

52. A prática de fato previsto como crime doloso constitui falta grave e, quando ocasione subversão da ordem ou disciplina internas, sujeita o preso provisório, ou condenado, sem prejuízo da sanção penal, ao regime disciplinar diferenciado, com as seguintes características:

I - duração máxima de 360 dias, sem prejuízo de repetição da sanção por nova falta grave de mesma espécie, até o limite de 1/6 da pena aplicada;

II - recolhimento em cela individual;

III - visitas semanais de duas pessoas, sem contar crianças, com duração de duas horas;

IV - o preso terá direito à saída da cela por duas horas diárias para banho de sol. (LEP, arts. 51 e 52) 


\section{S Linguagens}

Os atos considerados indisciplinados deverão ser combatidos de modo que o sujeito se adéque ao ambiente de controle, que se faz por meio de sansões que podem ser aplicadas:

53. Constituem sanções disciplinares:

I - advertência verbal;

II - repreensão;

III - suspensão ou restrição de direitos;

IV - isolamento na própria cela, ou em local adequado, nos estabelecimentos que possuam alojamento coletivo, observado o disposto no artigo 88 desta Lei*;

$\mathrm{V}$ - inclusão no regime disciplinar diferenciado. (LEP, art. 53)

A mesma lei que prevê as punições e sanções à liberdade do condenado, também busca resguardar seu corpo da violência física e simbólica ao garantir que "o condenado será alojado em cela individual que conterá dormitório, aparelho sanitário e lavatório (LEP, art. $88)$.

Em contrapartida, tendo em vista o bom comportamento reconhecido em favor do condenado, de sua colaboração com a disciplina e de sua dedicação ao trabalho, a LEP autoriza aos presos que se submeterem ao seu regime disciplinar recompensas que vão do elogio à concessão de regalias (arts. 55 e 56, I e II, LEP), ficando a cargo da legislação local e dos regulamentos de cada unidade estabelecer a natureza e a forma de concessão de regalias.

Quando o preso já se encontra na unidade cumprindo pena, diversos dispositivos atuam para a manutenção da disciplina, nos moldes previstos pela Lei de Execução Penal. Entre eles, pode-se citar a arquitetura de construção da unidade penitenciária, as regras de abrandamento e de agravamento de pena, a rotina imposta na unidade e também a figura do Agente Penitenciário, considerado o servidor público que atua no âmbito do sistema penitenciário como o elo entre a administração pública e o encarcerado. É ele o responsável pela custódia e manutenção do internado enquanto custodiado pelo sistema penitenciário, pelo cumprimento das rotinas, pela aplicação dos benefícios e das sanções. Sendo assim, as disposições sobre direitos e deveres estipulam práticas a serem assumidas por ambos os grupos.

Como orientação para o trabalho desses profissionais, o Departamento Penitenciário DEPEN-PR elaborou um manual intitulado de Práticas de Segurança nas Unidades Penais do Paraná (2011), que traz informações sobre as atribuições de cada setor de uma unidade, bem 


\section{Singuagens}

como as atribuições de cada um dos funcionários que nela trabalham. Observa-se, portanto, que, se há um poder que cerceia a liberdade de ir e vir dos apenados e lhes impõe uma disciplina a seguir, da mesma maneira, esse poder incide sobre os funcionários que devem seguir regras e também disciplinar seus corpos e suas ações nesse ambiente de trabalho.

Entre as várias questões abordadas nesse manual, foi recortado o uso da força por parte dos agentes como forma de manter a disciplina em casos mais graves de desordem, dado o fato que uma reclamação recorrente em rebeliões é de maus tratos e agressões por parte dos funcionários. Tal esclarecimento se torna necessário, dado o fato de que a Lei de Execuções Penais, em seu artigo 40, impõe a todas as autoridades o respeito à integridade física e moral dos condenados e dos presos provisórios, impedindo assim, a banalização do uso de determinados meios de coerção como o é o uso da força.

O Manual (2011, p. 35) define força como "toda intervenção compulsória sobre o indivíduo ou grupos de indivíduos, reduzindo ou eliminando sua capacidade de autodecisão". As situações diárias exigem do agente uma postura adequada do uso da força, de modo a respeitar princípios éticos, morais e legais. Segundo tal documento (2011, p. 35),

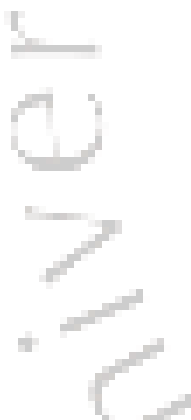

A doutrina do uso da força foi recomendada pela Organização das Nações Unidas ONU, através dos "Princípios Básicos para o Uso da Força e da Arma de Fogo", e o Brasil, como país membro da ONU, está comprometido com a adoção- dos mencionados princípios. Sendo a aplicação da Lei uma das tarefas elementares da Polícia, admite-se que esta utilize em determinadas circunstâncias a força necessária e na medida adequada, observando-se os princípios éticos e legais de necessidade e proporcionalidade no cumprimento do dever legal.

A orientação sobre o uso da força presente no caderno está embasada em um código mais amplo. Trata-se do Código de Conduta para os Encarregados da Aplicação da Lei (CCEAL), o qual foi proposto pela Assembleia Geral das Nações Unidas (ONU), em 19 de dezembro de 1979 e estabeleceu padrões para as práticas de aplicação da lei, conforme os direitos e liberdades humanas. Tais condutas devem ser cumpridas especialmente pelos poderes de prisão ou detenção. O CCEAL consiste em oito artigos e pertence à categoria dos instrumentos que proporcionam normas orientadoras aos governos sobre questões relacionadas com direitos humanos e justiça criminal. $\mathrm{O}$ uso da força é abordado nos seguintes artigos (ONU, 1979): 
$3^{\circ}$. Empregar a força quando estritamente necessário e na medida exigida para o cumprimento do seu dever;

$5^{\circ}$. Não poderá infligir, instigar ou tolerar qualquer ato de tortura, qualquer outra pena ou tratamento cruel, desumano ou degradante, nem invocar ordens superiores ou circunstanciais excepcionais como justificação para tal ato;

$6^{\circ}$. Assegurar a proteção da saúde das pessoas à sua guarda, bem como a prestação de cuidados médicos sempre que necessário;

Embora o agente penitenciário não esteja subordinado legalmente à instituição militar, o Código de Processo Penal Militar (Brasil, 1969) serve como referência quanto ao uso da força:

Art. 234 - o emprego da força só é permitido quando indispensável, no caso

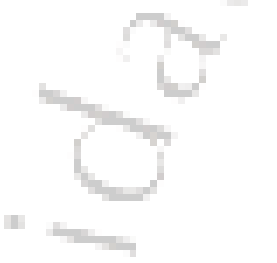
de desobediência, resistência ou tentativa de fuga. Se houver resistência da parte de terceiros, poderão ser usados os meios necessários para vencê-la ou a defesa do executor ou seus auxiliares, inclusive a prisão do ofensor. De tudo se lavrará subscrito do executor e de duas testemunhas.

Ao perceber a necessidade do uso da força, deve-se ponderar se o nível de força a ser utilizado é proporcional ao nível de resistência oferecida, pois se mal calculado, o seu uso pode acarretar conflitos maiores, exposição a situações perigosas e responsabilidade civil e criminal. Para que isso não ocorra, alguns princípios são essenciais para se justificar a aplicabilidade da força: legalidade; necessidade, conveniência e proporcionalidade.

O uso progressivo da força pode ser dividido em níveis diferentes, de forma gradual. Os níveis de força, de acordo com o Caderno de Segurança (2011, p.39), deverão ser aplicados conforme se adequarem melhor às circunstâncias dos riscos encontrados, bem como a ação dos indivíduos envolvidos durante determinada crise:

a) Nível 1 - presença física. A mera presença física, muitas vezes, será o suficiente para conter determinadas situações de conflitos.

b) Nível 2 - verbalização. Baseia-se na habilidade de comunicação, em que a mensagem é muito importante. A escolha correta das palavras a serem empregadas poderá produzir eficácia na resolução do conflito, através de negociação, mediação e persuasão. É de extrema importância manter o contato visual com o indivíduo, manter o tom de voz no intuito 


\section{Linguagens \& Cidadania}

de conquistar a confiança do mesmo e estar preparado para elevá-lo caso perceba algo de errado. Evite discutir, procure não ficar nervoso mantendo o profissionalismo sem desferir ameaças, até que a situação esteja contornada.

c) Nível 3 - controle de contato ou controle de mãos livres. Em determinadas situações poderá ser possível dominar o indivíduo fisicamente, utilizando-se de técnicas de imobilização e condução.

d)

Nível 4 - técnicas de submissão (controle físico). Emprego de força suficiente para superar a resistência do indivíduo, permanecendo vigilante em relação aos sinais de um comportamento mais agressivo.

e) Nível 5 - táticas defensivas não-letais. Caracteriza-se pela utilização de todos os métodos não-letais, através de forçamento de articulações e uso de equipamento de impacto (p. ex. tonfas).

A partir desse escalonamento, pode-se observar que o uso legítimo da força não se confunde com truculência. Como assevera Balestreri (apud Caderno de Segurança, 2011, p. 40): “A fronteira entre a força e a violência é delimitada, no campo formal, pela lei, no campo racional pela necessidade técnica e, no campo moral pelo antagonismo que deve reger a metodologia de policiais e criminosos".

A descrição dessa série enunciativa permite observar como a disciplina é discursivizada no ambiente prisional incidindo sobre os corpos de agentes e detentos. Foucault estuda a disciplina da sociedade moderna a partir de um contraponto com as formas disciplinares de tempos anteriores. Seu estudo demonstra que a disciplinarização dos corpos partiu da visibilidade da ação corretiva para o trabalho preventivo. Dessa forma, as marcas da punição no corpo foram substituídas pelo processo de docilização que passa pela disciplinarização do sujeito. Tal disciplina é regulamentada na atualidade brasileira pela Lei nº 7210/1984 - Lei de Execução Penal e, mais especificamente no Paraná, pelo caderno de segurança elaborado pelo DEPEN, que orientam, no caso do sistema penitenciário, as condutas dos servidores e dos custodiados.

Uma das práticas que contribuem para o estabelecimento dessa disciplina é o uso da força por parte dos agentes. O Código de Conduta para os Encarregados da Aplicação da Lei

Linguagens \& Cidadania, v. 19, jan./dez., 2017. 


\section{S Linguagens}

(CCEAL) orienta uma graduação do uso da força com o objetivo de alcançar a disciplina. Ela parte da simples presença coercitiva, o que remete a vigilância constante instaurada pelo modelo panóptico, descrito por Foucault. Passa pela etapa do diálogo e chega ao enfrentamento físico. Essa prática, discursivizada e regulamentada por manuais e documentos atua numa contradição. Por um lado busca estabelecer filiação com as formas modernas de punição, evitando que o corpo seja castigado e tornando o exercício do poder menos visível nos corpos dos detentos. Por outro lado, retoma a memória de uma punição que se inscreve no corpo, caso as formas mais brandas não surtam efeito de disciplinarização e os confrontos se agravem. A possibilidade de que a disciplina seja estabelecida pelo uso da força física efetua um movimento de recuo histórico em que as práticas de controle e poder se inscrevem no corpo e tornam visíveis as suas marcas.

\section{CONSIDERAÇÕES FINAIS}

Neste artigo, procurou-se discutir sobre as formas de controle e disciplinarização presentes no sistema penitenciário atual. Para tanto, partiu-se da discussão de Foucault a respeito das práticas de poder sobre o corpo, cada vez mais sutis, porém não menos eficientes; observou-se como as regras e a disciplina estão previstas em leis nacionais em relação ao contexto prisional e por fim, descreveu-se como essas disciplinas regulamentadas por lei se inscrevem em práticas sugeridas tanto aos custodiados quanto aos agentes penitenciários, por meio do uso da força, o que demonstrou que tais práticas coincidem com os princípios de docilização dos corpos apresentados por Foucault.

Foucault propôs o exercício do poder baseado em forças de coerção que atuam sobre os sujeitos e em estratégias de resistência pelas quais os sujeitos tentam escapar a esse poder. O ambiente prisional torna muito visíveis as relações de poder de Estado que, para gerir sua população, classifica os indivíduos em cidadãos de bem e criminosos e separa e gere a vida dos criminosos. Ainda que, com o passar do tempo, as formas de punição tenham mudado e deixado de usar de agressões físicas, estar encarcerado trata-se necessariamente de uma punição física, na medida em que impede a livre movimentação do corpo, o uso de roupas e produtos desejados e impinge o uso de algemas e a submissão a revistas constantes. Desse modo, será sempre um lugar de embate entre o Estado - representado por seus funcionários - e 


\section{S Linguagens}

os detentos.

Nessa teia de poder, cabe ao Estado impor a disciplina e preservar a segurança de todos: da população contra os detentos e, dos próprios detentos, quando sob sua custódia. E cabe aos detentos, resistir à punição que lhe é aplicada, seja ela uma agressão ou uma restrição física da liberdade. Colocados nesse lugar de resistir, compreende-se porque os detentos reclamam de agressões: mesmo quando o exercício do poder não visa a supliciar seus corpos, a imposição da disciplina no ambiente prisional atua sobre seus corpos.

\section{REFERENCIAS}

BERT, J.F. Pensar com Michel Foucault. São Paulo: Parábola, 2013.

BRASIL. Lei de Execução Penal. DOU Brasília, DF, 05 out 1988, LEP (Lei n 7.210, de 11 de julho de 1984).

BRASIL, Código de Processo Penal Militar. DOU Brasília, DF, 21 de outubro de 1969. (Lei $\mathrm{n}^{\circ}$ 1002).

BALESTRERI, R. B. Direitos Humanos: Coisa de Polícia. In PARANÁ. Departamento Penitenciário do Paraná. Cadernos do DEPEN. Práticas de Segurança nas Unidades Penais do Paraná. Curitiba, 2011.

FISCHER, R. M. B. Trabalhar com Foucault: Arqueologia de uma paixão. Belo Horizonte: Autêntica Editora; 2012.

FOUCAULT, M. Vigiar e Punir: o nascimento da prisão. $20^{\mathrm{a}}$ ed. Tradução Raquel Ramalhete. Petrópolis, RJ: Vozes, 1999.

Microfísica do poder. Tradução de Roberto Machado. Rio de Janiero: Graal, 2009.

MACHADO, R. Por Uma genealogia do poder. In: FOUCAULT, M. Microfísica do Poder. Rio de Janeiro: Graal, 1999.

ONU. Organização das Nações Unidas. Código de Conduta para os Funcionários Responsáveis pela Aplicação da Lei. Assembleia Geral das Nações Unidas, resolução 34/169, de 17 de Dezembro de 1979. Disponível em: <http://www.gddc.pt/direitoshumanos/textos-internacionais-dh/tidhuniversai s/ dhaj-pcjp-18.html>. Acesso em: 18 jan 2015 .

PARANÁ. Departamento Penitenciário do Paraná. Cadernos do DEPEN. Práticas de Linguagens \& Cidadania, v. 19, jan./dez., 2017. 


\section{Linguagens \& Cidadania}

Segurança nas Unidades Penais do Paraná. Curitiba, 2011.

PARANÁ. Estatuto Penitenciário do Paraná. DOU, Brasília, DF, nº . 4625, 31 de outubro de 1995.

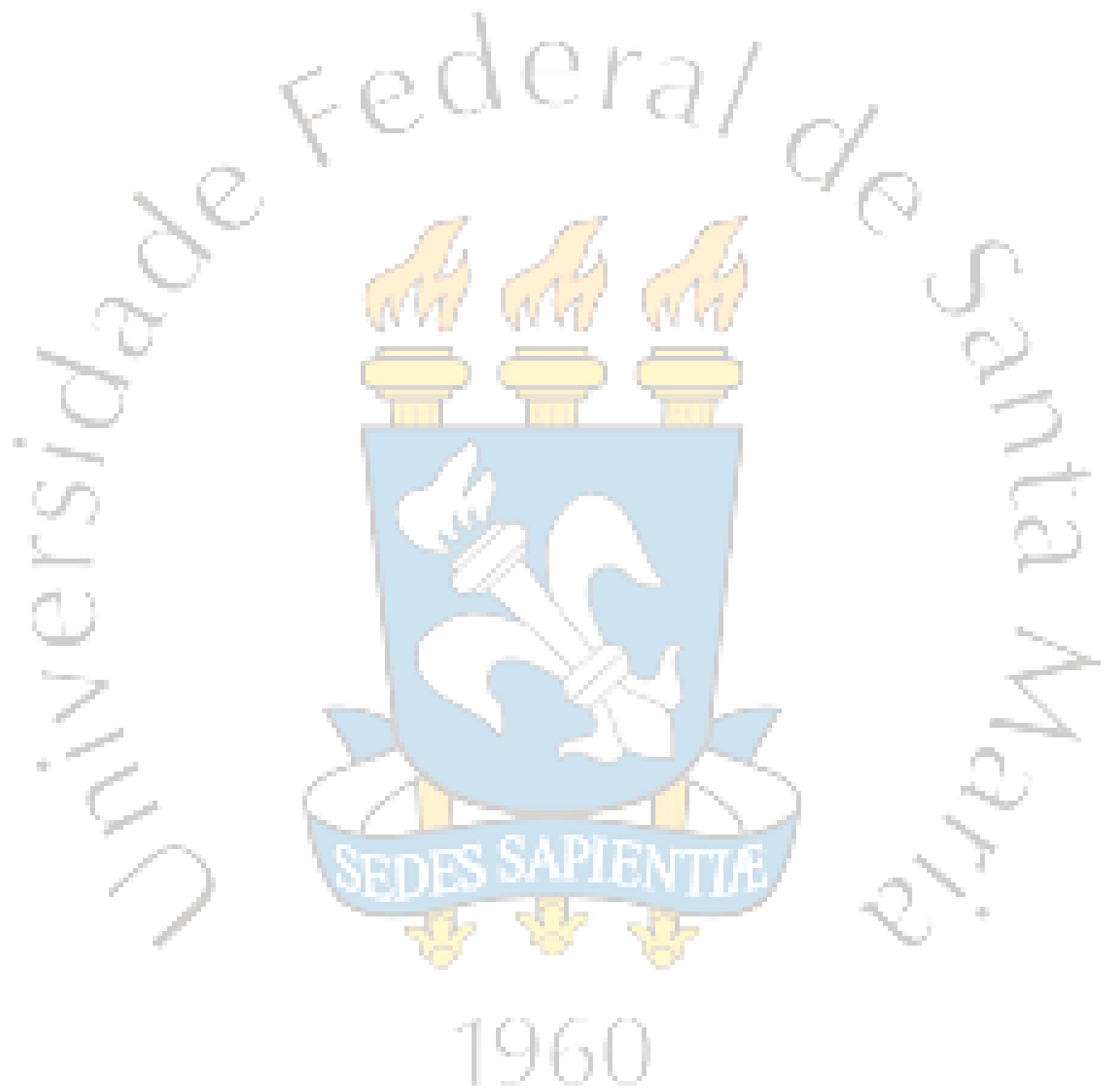

Linguagens \& Cidadania, v. 19, jan./dez., 2017. 